\title{
Observatorio Económico
}

En 2002 cinco Isapres (Banmédica, Colmena, Consalud, ING y Vida Tres) bajaron la cobertura que ofrecían a sus afiliados pero mantuvieron los precios. Es decir, los afiliados

terminaron con planes de salud peores que los que tenían antes y por el mismo valor. En 2005 la Fiscalía

Nacional Económica (FNE) fue al

Tribunal de Defensa de la Libre

Competencia (TDLC) y acusó de colusión a las cinco Isapres. El 12 de julio pasado el TDLC, en "fallo dividido" (3 votos a favor y 2 en contra), determinó que no existían suficientes pruebas de que las Isapres se hubieran coludido para disminuir la cobertura de sus planes.

Lo que sigue en las próximas páginas es un racconto del caso y un análisis del fallo. Hay que considerar que el sistema de apreciación de la prueba que rige al Tribunal es el de la sana crítica. Este sistema exige a los jueces valorar las pruebas de acuerdo a su experiencia, a las reglas de la lógica

formal y a la teoría económica. Ellos están obligados a fundamentar

sus fallos dando cuenta de toda la

evidencia rendida, más allá de la apreciación que hagan de la misma.

En nuestra opinión el fallo de mayoría tiene errores fundamentales.

Se ignoró parte sustancial de

la prueba rendida, algo del razonamiento seguido por los jueces es contrario a la teoría económica

y además -como lo reconoce implícitamente el fallo de minoría- es contrario a la lógica. Por otra parte,

el fallo tiene aspectos positivos: es preciso y acertado en algunos puntos de controversia y sienta precedentes

importantes para el futuro de la industria de seguros de salud. Sin embargo, el sabor final es amargo.

\section{Las fallas del Fallo Isapres}

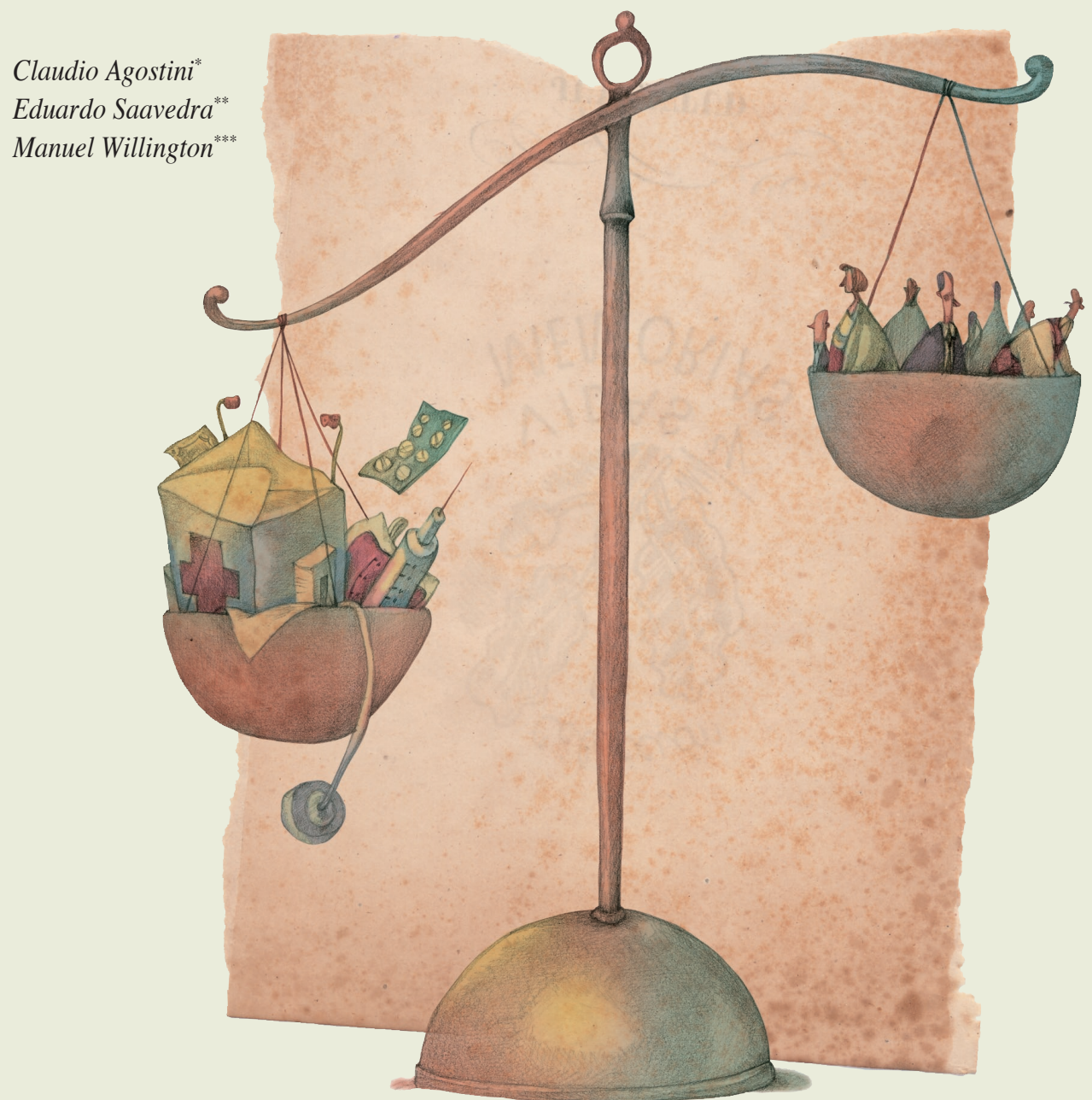

En el segundo trimestre de 2002 las Isapres requeridas iniciaron un proceso de sustitución de planes con cobertura "100/80" por otros con cobertura " $90 / 70 "$.

El proceso de sustitución de planes se hizo en forma llamativamente "paralela" por parte de las Isapres, a excepción de Consalud, cuya intensidad de sustitución fue inferior a la de las otras cuatro en los primeros seis meses de ese año. Esta disminución de cobertura no fue acompañada por una baja en los precios ni aumentos en los topes.

Una característica sobresaliente de los mercados de seguros de salud es la existencia de "riesgo moral": los asegurados, en la medida que no afronten copagos significativos, tienen incentivos a sobreutilizar el seguro. Este problema puede verse agravado por el fenómeno de "inducción de demanda", según el cual el médico puede inducir al paciente a realizarse

* PhD en Economía de University of Michigan, Académico de la Facultad de Economía y Negocios de la Universidad Alberto Hurtado.

** PhD en Economía de Cornell University, Académico de la Facultad de Economía y Negocios de la Universidad Alberto Hurtado. *** PhD en Economía de University of Pennsylvania, Académico de la Facultad de Economía y Negocios de la Universidad Alberto Hurtado.

Los autores, contratados por la fiscalía nacional económica, realizaron en diciembre de 2005 un informe para ser presentado al tdlc. Este documento está parcialmente basado en aquel informe.

El primer valor hace referencia al porcentaje de la cobertura que recibe el afiliado en caso de hospitalizaciones y el segundo en caso de prestaciones ambulatorias. Estos valores son indicadores imperfectos de la cobertura efectiva, ya que típicamente existen "topes" por prestaciones que indican el valor máximo que pagará la Isapre. 
más consultas o exámenes que los económicamente razonables. Ni el médico ni el paciente afrontan el costo de ellos.

\section{La acusación de la Fiscalía}

De acuerdo a la acusación de la Fiscalía, este proceso gradual y paralelo de sustitución de planes sólo puede explicarse por la existencia de un acuerdo colusivo. Las aseguradoras obtenían, antes del alegado acuerdo, utilidades sobre el patrimonio de alrededor del $30 \%$; por lo que, de acuerdo a la Fiscalía, el cambio de los productos ofrecidos no sería una respuesta a la existencia de pérdidas, sino simplemente un acuerdo que les permitió aumentar sus beneficios. Ellos crecieron en 25 mil millones de pesos entre 2002 y 2004 para el conjunto de Isapres acusadas.

El acuerdo habría sido en detrimento de los consumidores quienes, sin una correspondiente disminución en las primas pagadas, vieron disminuida la calidad del seguro que adquirían.

\section{La defensa de las Isapres}

La defensa de las Isapres se basó en varios argumentos complementarios, aunque no necesariamente coherentes entre sí. En respuesta a los argumentos presentados por la Fiscalía, se adujo que:

a) la copia de planes es característica en la industria de los seguros de salud tanto por la publicidad de las mismas empresas como por la comunicación fluida que existe entre vendedores de distintas empresas;

b) las rentabilidades de las empresas no deben medirse como porcentaje del patrimonio (dado el requisito de capital relativamente bajo que poseen) ni de los activos contables, ya que parte fundamental del patrimonio es la cartera de afiliados que, de acuerdo a las normas contables vigentes, no es valorizada. Correspondería, por lo tanto, de acuerdo a las propias Isapres, utilizar alguna medida que guarde relación con los ingresos operacionales. Medidas así, las Isapres no presentaban rentabilidades excesivas en 2002;

c) el mercado relevante de seguros de salud incluye a Fonasa, por lo que las Isapres requeridas no tienen poder de mercado: frente a un aumento de precio o baja en la calidad de los planes de salud una proporción importante de los afiliados se puede cambiar a Fonasa;

d) no existen barreras a la entrada en la industria dados los bajos requisitos en términos de capital; ${ }^{2}$

e) la disminución de cobertura de "carátula" de los planes de " $100 / 80 "$ a " $90 / 70 "$ es sólo una de las varias dimensiones que determinan la cobertura efectiva del plan;

f) no hay abuso de poder de mercado por cuanto los nuevos planes " $90 / 70$ " son más convenientes para los consumidores ya que limitan el problema del riesgo moral, lo que permite ofrecerlos a un menor costo que los planes “100/80”; y

g) en el periodo 2002-2004 hubo una rotación importante de afiliados entre las Isapre abiertas y entre ellas y Fonasa.

\section{Crítica con buena salud}

Es importante tener presente que en materia de libre competencia la apreciación o valoración de la prueba debe realizarse de acuerdo a las reglas de la Sana Crítica, y no con la regla de la Prueba Tasada que aún predomina en el sistema judicial chileno. "Las reglas de la sana crítica, no son otras que las que prescribe la lógica y derivan de la experiencia, las primeras con carácter permanente y las segundas, variables en el tiempo y en el espacio." 3 Por el contrario, en el sistema de prueba tasada la ley determina el peso relativo que los jueces deben asignar a cada prueba.

Es cierto que la Sana Crítica brinda más discrecionalidad a los jueces que la prueba tasada. Esta discrecionalidad, sin embargo, no llega al nivel que permite el sistema de Libre
Convicción, según el cual el juez dicta la sentencia de acuerdo a su, valga la redundancia, íntima convicción. "Dentro de este método (Libre Convicción) el magistrado adquiere el convencimiento de la verdad con la prueba de autos, fuera de la prueba de autos y aún contra la prueba de autos". ${ }^{4}$

\section{El hecho de que se haya} determinado que el mercado relevante es el de las Isapres abiertas es muy importante. Si se hubiese concluido que las Isapres y Fonasa pertenecen al mismo mercado, se habría abierto la puerta a cualquier tipo de comportamiento anticompetitivo por parte de las primeras, ya que en ningún caso tendrían poder de mercado.

De acuerdo al mismo autor, las reglas de la Sana Crítica son "las reglas del correcto entendimiento humano". Couture dice que ellas reúnen la lógica y la experiencia del juez. Pero "el juez que debe decidir con arreglo a la sana crítica, no es libre de razonar a voluntad, discrecionalmente, arbitrariamente. Esta manera de actuar no sería sana crítica, sino libre convicción. La sana crítica es la unión de la lógica y la experiencia sin excesivas abstracciones de orden intelectual..."

La Sana Crítica se emplea cada vez más en el sistema jurídico chileno. La Ley 19.968 sobre tribunales de familia y el Código Procesal Penal establecen que al apreciar la prueba los

${ }^{2}$ Es interesante notar la contradicción entre este argumento y aquél que señala que parte fundamental de los activos está constituido por la cartera de clientes.

Hugo Alsina (1956): Tratado Teórico Práctico de Derecho Procesal Civil y Comercial (Buenos Aires, Ediar S. A. Editores).

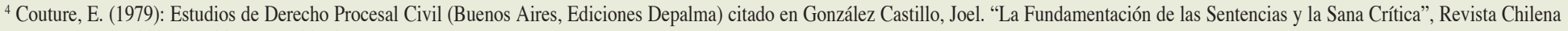
de Derecho, abr. 2006, vol.33, no.1, p.93-107 
jueces "no podrán contradecir los principios de la lógica, las máximas de la experiencia y los conocimientos científicamente afianzados”. Es más: se obliga a los jueces a que en la fundamentación de la sentencia se hagan cargo de toda la prueba rendida, incluso desestimada -indicando en tal caso las razones tenidas en cuenta para hacerlo-. En la citada ley, la idea es que en la sentencia esté contenido "el razonamiento utilizado para alcanzar las conclusiones".

De acuerdo al Profesor de Derecho Civil de la Universidad Católica Joel González Castillo, cuatro elementos identifican y componen la regla de la Sana Crítica en a la legislación chilena: la necesidad de ajustarse a los principios de la lógica, a la experiencia adquirida de los jueces, a los conocimientos científicos afianzados y, finalmente, la necesidad de justificar la sentencia dando cuenta de los razonamientos y elementos probatorios que permiten arribar a las conclusiones. Sin embargo, el propio González Castillo da cuenta de que los jueces no cumplen con este requisito de justificar la sentencia: “...lo que se acostumbra ver (...) es que luego de una simple relación de la prueba rendida -que en la forma aparente de un análisis, es más bien un resumen de ella- seguida de la genérica afirmación 'y que habiéndose apreciado la prueba en conciencia' las causas se fallan sin más. Ese es todo el razonamiento que muchas veces se expresa en los textos de los fallos." 5

\section{Colusión Explícita y Tácita}

En la literatura económica se habla de colusión o de un "resultado colusivo" en un mercado particular cuando los precios observados son mayores que los que corresponden en un "resultado competitivo". ${ }^{6}$ Se distinguen dos tipos de acuerdos colusivos: los explícitos, en que los participantes actúan a través de un cártel organizado; y los tácitos, en los que obviamente no existe un acuerdo formal.

La colusión tácita ocurre cuando los involucrados toman decisiones paralelas, conscientes de que la decisión de cada uno es similar a la del resto y sabiendo que este paralelismo juega un rol fundamental en la decisión de cada firma. Es decir que para cada firma su comportamiento es "óptimo" en tanto las otras firmas se comporten de igual manera. Quedan excluidas, por lo tanto, aquellas acciones paralelas y conscientes en que la decisión de cada una de las firmas es "óptima" independiente de que las otras actúen de manera paralela o no.?

Parte fundamental de la tarea del tribunal (una vez acreditados ciertos elementos básicos como el paralelismo de las acciones, la posición de dominio de los acusados y el perjuicio provocado a otra parte) es identificar si el comportamiento de cada firma era óptimo más allá del comportamiento que siguiesen sus rivales (y si es así, no puede descartarse que las firmas actuaron de manera competitiva). Para ello las partes involucradas en el caso presentan evidencia sobre "factores adicionales" que son consistentes con su postura y no con la del adversario. El fallo del tribunal se basa entonces en la valoración que se haga de esta evidencia o de otros factores adicionales que el mismo tribunal identifique.

Es importante destacar que ambos tipos de acuerdos colusivos van en detrimento de los consumidores. Si bien existe algún grado de debate en la economía respecto a si ambos tipos de acuerdos debieran sancionarse o sólo los explícitos (ver, por ejemplo, en Motta 2004 argumentos a favor de esta última posición), la ley chilena castiga a los dos cuando considera entre las prácticas contrarias a la libre competencia “a) Los acuerdos expresos o tácitos entre agentes económicos, o las prácticas concertadas entre ellos, que tengan por objeto fijar precios de venta o de compra, limitar la producción o asignarse zonas o cuotas de mercado, abusando del poder que dichos acuerdos o prácticas les confieran" (D.L. 211, art. $3^{\circ}$ )

\section{Lo que el fallo rescató}

\section{El mercado relevante}

El primer punto de controversia fue respecto al mercado relevante: la Fiscalía argumentó que éste estaría conformado sólo por las Isapres abiertas, en tanto que las Isapres requeridas argumentaron que debía incluirse a Fonasa. El tribunal dejó fuera a Fonasa. Si el tribunal hubiese acogido el punto de vista de las Isapres, la participación de las requeridas sería de alrededor del 30\%, lo que difícilmente constituiría una posición de dominio en el mercado. El tribunal determinó que el mercado relevante era el de las Isapres abiertas, y en ese caso la participación de las requeridas era cercana al $80 \%$.

Para tal determinación, el TDLC consideró la información estadística disponible que ilustra la segmentación por tipo de renta y por edad de los afiliados a Isapre y Fonasa. Esta segmentación se explica por la diferente naturaleza de ambos seguros: Fonasa tiene una lógica solidaria, brinda una cobertura que es independiente de la edad, sexo y número de cargas del cotizante, y depende de manera inversa del aporte que hace el afiliado: los afiliados de mayores ingresos tienen copagos mayores. Por el contrario, el sistema de Isapre tiene una lógica individualista: las personas de mayores ingresos, menor riesgo y con menos cargas pueden acceder a seguros más completos.

El fallo del tribunal valoró también el informe que elaboramos para la Fiscalía. Él muestra evidencia econométrica de cómo la probabilidad de estar afiliado a una Isapre abierta disminuye cuando el ingreso autónomo del hogar disminuye, cuando el número de personas en el hogar aumenta, cuando el jefe de hogar es mujer y cuando él o ella reporta tener un estado de salud "malo". Esta probabilidad es más baja para los jóvenes y para los adultos mayores.

Si las cinco Isapres requeridas representan alrededor del 80\% de los afiliados, en la medida que existan barreras a la entrada y/o salida de la industria ellas tendrían un enorme poder de mercado.

${ }^{5}$ Este comentario, vale la aclaración, no se refiere en particular a las sentencias del TDLC.

Motta (2004)

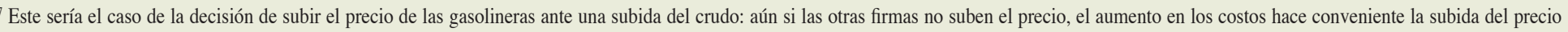
propio. 


\section{Observatorio Económico}

El hecho de que se haya determinado que el mercado relevante es el de las Isapres abiertas es muy importante. Si se hubiese concluido que las Isapres y Fonasa pertenecen al mismo mercado, se habría abierto la puerta a cualquier tipo de comportamiento anticompetitivo por parte de las primeras, ya que en ningún caso tendrían poder de mercado.

\section{Las barreras a la entrada}

Para que la potencial entrada de competidores sirva como presión competitiva y permita disuadir potenciales acuerdos colusorios, ella debe ser suficientemente probable, rápida y relevante en magnitud. En el fallo, el Tribunal entiende que estas tres condiciones no estarían dadas en el caso de los seguros de salud privados. De acuerdo al análisis, la capacidad de un nuevo entrante de formar redes atractivas de prestadores para los afiliados podría verse limitada por los diferentes grados de integración vertical existentes entre las Isapres del mercado y algunos prestadores relevantes.

Además, producto de las restricciones que existen para los traspasos de afiliados, puede ser muy difícil para una Isapre entrante construir una cartera de clientes de tamaño importante: por un lado, aquellos que tienen enfermedades crónicas se encuentran virtualmente imposibilitados de cambiarse de aseguradora por la exclusión de preexistencias que la nueva aseguradora aplicaría o porque simplemente serían rechazados; y por otro, por la restricción que hay sobre todos los afiliados que pueden cambiarse sólo una vez al año (al término de su contrato).

El Tribunal valoró la simulación presentada en el informe que elaboramos para la Fiscalía según la cual, en el mejor de los casos, una Isapre entrante alcanzaría un 7\% del mercado sólo después de dos años. Al cabo de cuatro años este porcentaje estaría entre el 8 y $9 \%$ del mercado.

\section{Otras características del mercado}

En los casos de colusión tácita, típicamente deben analizarse las condiciones del mercado que, en teoría, favorecen o entorpecen que los actores lleguen a acuerdos contrarios a la libre competencia.
Entre las características del mercado de seguros que, a priori, facilitarían la colusión, el Tribunal reconoce tres adicionales a la existencia de barreras a la entrada: el reducido número de competidores, la transparencia "inter-Isapres" en la información sobre planes disponibles y sus precios y la frecuente interacción entre las empresas en instancias como la Asociación de Isapres y reuniones de gerentes. De hecho, las mismas Isapres reconocen la copia de planes y la comunicación fluida entre sus vendedores.

Entre los factores que entorpecerían un acuerdo, el Tribunal destaca las asimetrías entre los actores, en particular respecto a los segmentos de ingreso que atienden las distintas aseguradoras.

\section{El paralelismo de las acciones}

A partir de la información estadística provista por las mismas Isapres requeridas el Tribunal concluyó que efectivamente existió un comportamiento paralelo en la sustitución de planes " $100 / 80$ " por " $90 / 70 "$. Este paralelismo es más fuerte en cuatro de esas Isapres (el proceso de sustitución seguido por Consalud es algo posterior al de las demás requeridas). Los Gráficos 3 y 7 de la sentencia del Tribunal ilustran este proceso de sustitución.

\section{Gráfico 3}

Participación de Ventas de Planes 90/70 en la oferta mensual total de cada requerida (\%)

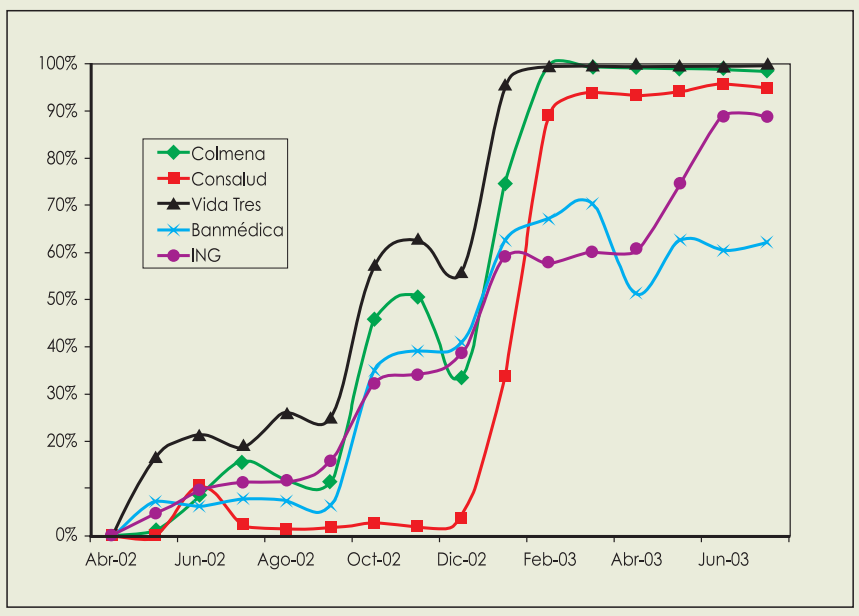

Gráfico 7

Intensidad de Sustitución

Cambio en la Participación \% de las Ventas Mensuales de Planes 90/70 (en el Total de Nuevas Afiliaciones de cada Isapre)

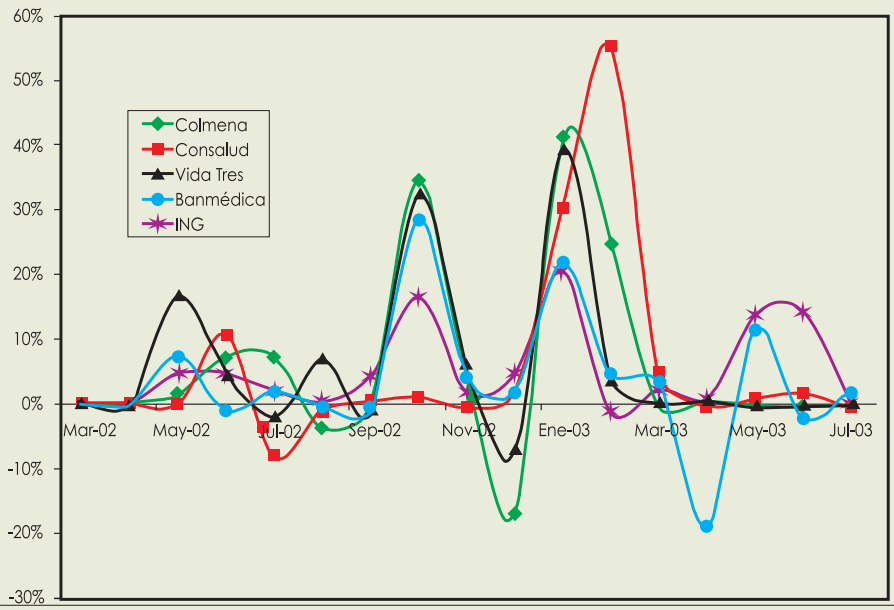


El Gráfico 3 indica el porcentaje de planes “90/70" vendidos cada mes como porcentaje del total de planes vendidos.

El Gráfico 7 del fallo presenta la evolución de los "esfuerzos de sustitución". Ellos están determinados por el cambio porcentual mensual respecto al mes anterior en el porcentaje que las ventas de planes “90/70" representaron sobre el total.

La coincidencia en el aumento de los esfuerzos de sustitución en los meses de octubre de 2002 y enero de 2003 es, a juicio del Tribunal, el indicio más importante del que se podría inferir un acuerdo colusorio entre cuatro de las Isapres requeridas.

\section{Los errores (y algún horror) del fallo}

Una vez acreditado que el comportamiento de las Isapres fue "paralelo", debe explicarse si corresponde a un acuerdo colusivo del cual podrían haber obtenido beneficios económicos en detrimento de los consumidores o a una reacción competitiva y no concertada. Para poder distinguir entre ambas hipótesis, deben analizarse argumentos o factores adicionales que sean consistentes con una hipótesis pero no con la otra.

De acuerdo al Tribunal, la defensa presenta tres argumentos que habrían inducido de manera natural (y no concertada) la decisión de sustitución de planes:

a) La mala situación económica general y la difícil situación de las Isapres debido a una creciente siniestralidad;

b) el contexto de incertidumbre regulatoria; $y$

c) la necesidad de incentivar un cambio cultural hacia la contención de costos.

A grandes rasgos, la valoración de estos argumentos que se hace en el fallo de la mayoría es la siguiente:

1) que si bien es efectivo que hubo una crisis a partir de 1997 y que impactó negativamente sobre la tasa de empleo, a inicios de 2002 ya existían indicios parciales de reactivación económica. Por otra parte, la cantidad de afiliados de ingresos superiores a $\$ 400.000$ de las Isapres requeridas venía creciendo desde 1999 (no así la cantidad de afiliados con ingresos inferiores a los $\$ 400.000$ ).

2) Respecto al argumento de la incertidumbre regulatoria, el Tribunal considera que al momento de iniciarse la sustitución de planes existía una importante incertidumbre por el proyecto de reforma que, en ese instante, parecía que afectaría a las Isapres. Sin embargo, a juicio del Tribunal, resulta improbable que la respuesta única a tanta incertidumbre fuera la misma en todas las Isapres requeridas.

3) que la "tasa de siniestralidad", medida como la razón entre costos e ingresos operacionales, subió entre 1996 y 2002, mientras que los resultados de operación bajaron. Ante esto, la disminución de las coberturas sería una respuesta racional para mitigar los problemas de riesgo moral (de pacientes y médicos) y así disminuir la siniestralidad. De acuerdo al Tribunal, a partir de 2002 el crecimiento de la tasa de siniestralidad de las Isapres requeridas habría disminuido, con una importante varianza entre las Isapres.

A partir de esta evidencia, no se descarta que la sustitución de planes haya sido motivada por la intención de mitigar los problemas de riesgo moral. Es lo que las Isapres afirmaron.

Pero el fallo de minoría disiente. Hace notar que la "tasa de siniestralidad" definida por las Isapres requeridas (y utilizada en el fallo de la mayoría) no tiene asidero en la teoría económica y, peor, su comportamiento al alza puede deberse a distintas razones. Una baja en los ingresos operacionales debida, por ejemplo, al ciclo económico, afectaría al alza a la "tasa de siniestralidad" sin que el problema de riesgo moral se hubiera afectado en modo alguno.

Más allá de este punto formal, de acuerdo a la información disponible en la Superintendencia de Salud (basada en información no auditada provista por las mismas Isapres), el total de prestaciones promedio por beneficiario entre los años 1996 a 2000 siempre creció: 9,9; 10,$2 ; 10,9 ; 12,3$ y 13 , por lo que una reacción razonable ante el alza de la siniestralidad es efectivamente disminuir la cobertura. Sin embargo, el hecho que sea una reacción "económicamente razonable" no es suficiente. Debe dilucidarse si el cambio de planes fue adoptado en un contexto de competencia o en uno de colusión, y para ello es imprescindible analizar otras variables adicionales y entender si sus comportamientos son consistentes con la libre competencia o con acuerdos colusivos.

A favor del principal argumento de la defensa -que la sustitución de planes y su simultaneidad fueron fruto de la competencia-, la sentencia afirma con una vaguedad de conceptos que estos ajustes involucraban "expectativas de efectos financieros relevantes". Y que en ese escenario una estrategia de competencia "podría haber estado conformada por (a) esfuerzos graduales y secuenciales en la venta de los nuevos planes ' $90 / 70$ ', a modo de testeo precautorio y a la vez exploratorio sobre las respuestas observadas, a posteriori, en el mercado, junto con (b) el ejercicio de un monitoreo cercano e intensivo (implementable, por ejemplo, mediante la entrega de incentivos contractuales al personal contratado como equipo de ventas) respecto de los ritmos (intensidades) de sustitución y venta de los nuevos planes '90/70'”. Esto, continuaba la sentencia, ocurría "aceptando la posibilidad que el retiro de los planes ' $100 / 80$ ' pudiera haber constituido una estrategia de competencia, y no necesariamente de colusión, para cada Isapre requerida, dados los procesos de cambio y ajuste entonces vigentes por el lado de la oferta (costos) y la demanda (lo último, relacionado a las fases del ciclo económico y a las mejoras introducidas gradualmente en la calidad de los planes ofrecidos por Fonasa);"

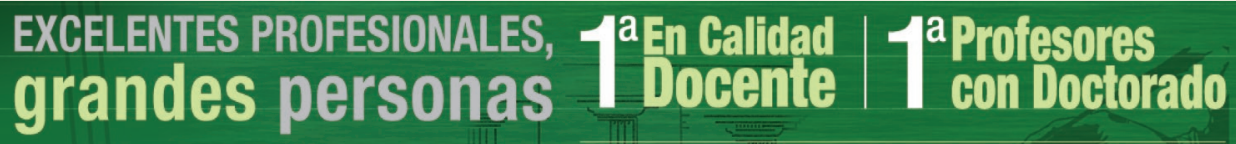

* Ranking de Universidades REVISTA QUE PASA, noviembre de 2006

Estudia Ingeniería Comercial e Ingeniería Comercial para Profesionales 
Como reconoce el tribunal, a inicios de 2002 ya existían indicios de recuperación económica, por lo que no es obvio que ese fuera el momento para introducir planes de menor calidad y menor precio. Menos evidente aún resulta que ante las mejoras en la calidad de los planes de un supuesto competidor (Fonasa) la respuesta sea bajar la calidad de los planes propios. Sorprende que el voto de mayoría del Tribunal haya aceptado la contradicción.

Respecto a los esfuerzos graduales "a modo de testeo precautorio y exploratorio sobre las respuestas observadas" en el mercado y al monitoreo cercano e intensivo de los ritmos de sustitución de planes, no es claro si el fallo se refiere a las respuestas por el lado de la demanda o por el lado de los otros competidores...

Un elemento esencial del análisis debiera haber sido si las acciones de las firmas son o no óptimas más allá de la reacción de sus competidoras: si la reducción en la cobertura de los planes por parte de una firma es óptima sólo en la medida que sus competidoras la sigan, el sustento de la hipótesis de competencia se transforma automáticamente en un argumento a favor de la de colusión.

El fallo reconoce que “...tanto en la hipótesis de colusión como en la de interdependencia oligopolística, e independientemente de las razones que hayan tenido las Isapres para hacerlo, este Tribunal puede dar por establecido que la sustitución de planes con cobertura de carátula ' $100 / 80$ ' por aquellos con cobertura ' $90 / 70$ ', les era mutuamente conveniente a las Isapres”.

¿Y por qué el fallo no las condenó entonces? Es evidente que las acciones son consistentes con la hipótesis de colusión: si un grupo relevante de empresas reduce la calidad del producto sin bajar el precio (y existen barreras a la entrada y la demanda por el bien es relativamente inelástica) sus beneficios deben aumentar. Esa es precisamente la razón por la cual las empresas tienen incentivos para coludirse. La razón por la cual esto podría no ser cierto si las firmas compiten tiene que ver con la participación de mercado que perdería la firma que inicia la reducción en la calidad... Pero este punto no fue analizado por el fallo de mayoría.
4

En nuestra opinión el fallo de mayoría tiene errores fundamentales. Se ignoró parte sustancial de la prueba rendida, algo del razonamiento seguido por los jueces es contrario a la teoría económica y además -como lo reconoce implícitamente el fallo de minoría- es contrario a la lógica

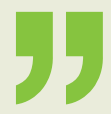

En esta etapa de la justificación el fallo falla (¡sí, yerra!). Considera que si una empresa, de manera no coordinada, decide reducir la cobertura con la esperanza de que las otras la "sigan", y sabe que si no es imitada por las "competidoras" puede dar marcha atrás sin soportar excesivos costos, entonces... ¡eso no es colusión!

El Tribunal estimó que es plausible sostener que las Isapres pensaron que la sustitución de los planes “ $100 / 80$ ” era conveniente y que, así las cosas, cualquiera de ellas, sin necesidad de coordinarse con otras, puede haber bajado la cobertura de carátula con la convicción de que las demás la seguirían, dado que les convenía. Es más, reconoce la misma plausibilidad en el hecho de que la sustitución de planes fue un proceso relativamente largo, que permitía a la empresa que hubiera iniciado el proceso analizar la reacción de la competencia y, en caso que las restantes Isapres hubiesen mantenido sus planes "100/80", ajustar o enmendar rumbo. "En efecto", dice el fallo, "el hecho que la sustitución de planes ' $100 / 80$ ' por planes '90/70' se haya iniciado en forma paulatina pudo tener por explicación que quien la inició quisiera conocer la reacción de la competencia antes de acelerar el proceso" (el subrayado es de los autores).
La sentencia continúa señalando que se puede deducir que el proceso de sustitución pudo ocurrir si la empresa que lo inició se formó la convicción de que sus competidores la seguirían "o que, en caso contrario, podría volver a ofrecer planes ' $100 / 80$ ' a los nuevos afiliados, sin haber sufrido en el intertanto pérdidas demasiado cuantiosas". Sin embargo, la sentencia deja abierta la posibilidad para que la empresa hubiera llegado a esta convicción no solo a través de un acuerdo colusorio, sino también a través de "un análisis de la estrategia que estimaba seguirían sus competidores, aunque en ese caso el riesgo de hacerlo sería mayor. Por lo anterior, el mero paralelismo no permite tener por acreditada la colusión objeto del requerimiento".

Y concluye luego que no hay en autos prueba de que lo que ocurrió sea consecuencia de un acuerdo colusivo o de la interdependencia oligopolística propia de la competencia. El problema es que la hipótesis de "interdependencia oligopolística" descrita no es tal, es colusión tácita. El comportamiento descrito por el tribunal es precisamente el de una firma que envía una señal a sus rivales para coordinar un equilibrio más conveniente para ellas. ${ }^{8}$ La teoría económica, a partir del desarrollo de la teoría de juegos, muestra sistemáticamente cómo un comportamiento de este tipo permite sustentar equilibrios con precios no competitivos en un mercado. Nuevamente sorprende que el Tribunal descarte implícitamente la teoría económica básica.

El informe que realizamos para la Fiscalía presenta tres "factores adicionales" que, a nuestro juicio, son consistentes con la hipótesis de colusión y no con la de competencia.

En el periodo de sustitución de planes las coludidas disminuyeron el gasto en publicidad y en fuerza de venta. ¿Fue una estrategia de no "robarse" clientes en el período en que se sustituían los planes tradicionales por otros de menor cobertura? Por el contrario, si como sostienen las Isapres se tratase de planes innovadores que en definitiva benefician al usuario y las Isapres estuviesen compitiendo con este nuevo producto, uno esperaría un aumento (o al menos mantención) de la publicidad y del gasto en personal de venta.

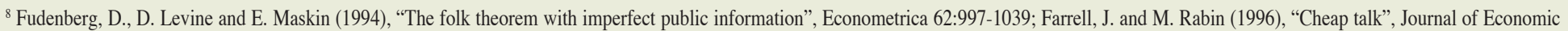

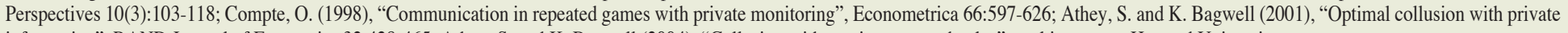
information", RAND Journal of Economics 32:428-465; Athey, S. and K. Bagwell (2004), "Collusion with persistent cost shocks," working paper, Harvard University. 
Además, en el periodo posterior al supuesto acuerdo colusivo, la rentabilidad medida como tasa de margen operacional (ingresos menos costos operacionales dividido por ingresos operacionales) tanto de las Isapres requeridas como de las no requeridas aumentó. Esto es característico de los acuerdos colusivos (quienes no suscriben el acuerdo son los que más se benefician) e inconsistente con la hipótesis de competencia, porque las empresas que innovaron debieran obtener mejores resultados que las otras.

Por otra parte, durante el periodo de sustitución de planes la tasa de rotación de afiliados entre las Isapres requeridas comparada con la misma tasa para las no requeridas, disminuyó. Más allá de la diversidad de variables en que las Isapres pueden competir, si efectivamente lo hacen esto debiera reflejarse en la cantidad de afiliados que se "roban" unas a otras.

Aunque el fallo de la mayoría sostiene que en teoría los gastos en publicidad y fuerza de ventas no debieran haber disminuido, considera que el comportamiento en cuanto a la publicidad en las requeridas fue heterogéneo y que además, tal como muestra nuestro estudio, éste ya venía bajando desde antes de 2002. Es curioso que todo el Tribunal, mayoría y minoría, coincide en que Consalud aumentó su publicidad porque no participó del acuerdo colusivo... ique el propio Tribunal estima que no se puede acreditar! ${ }^{9}$

Si bien efectivamente el estudio da cuenta de esta baja anterior a 2002, el fallo desestima otra parte del estudio: la que dice que en el segundo trimestre de 2002 hay un "quiebre": un cambio en el nivel de estos gastos para las Isapres requeridas que no ocurre en las otras. Respecto al gasto en fuerzas de venta, el tribunal considera que muestra un comportamiento homogéneo y a la baja en el 2002, pero no en el 2003. El fallo concluye reconociendo que estos antecedentes podrían ser, en principio, compatibles con un acuerdo colusivo o concertación de las requeridas, especialmente durante 2002. "Sin embargo, y como se ha argumentado previamente, también es posible pensar en un conjunto de otros factores relevantes que podrían adicionalmente condicionar los niveles óptimos de estos gastos, y sobre los cuales no existe información alguna en autos".
Este argumento es vago y sencillamente incorrecto; la justificación del fallo ignora la naturaleza de la evidencia presentada. El análisis econométrico que realizamos en el informe de la Fiscalía compara el grupo de Isapres requeridas con las no requeridas (y a ambos grupos a través del tiempo) y se hace cargo de controlar el efecto que podrían tener variables específicas de cada Isapre que no hayan cambiado en el periodo de análisis.

Esos "otros factores relevantes" sobre los que no existe información en los autos debieran, para invalidar el análisis de la Fiscalía, afectar sólo a las Isapres requeridas, y aparecer coincidentemente alrededor del segundo trimestre del año 2002. Si existiese esa misteriosa información tan específica y exculpatoria, ¿por qué no fue provista por las requeridas?

Más aún, de acuerdo a la regla de la Sana Crítica, el fallo de la mayoría debería explicitar cuál es este conjunto de factores adicionales relevantes, de lo contrario es imposible contrastarlos con el resto de la evidencia y someter el argumento que sustenta el fallo a las reglas de la lógica.

La robustez de los resultados del informe que realizamos para la Fiscalía respecto a gastos en publicidad y fuerza de venta es criticada en un informe de Consalud del que se hace eco el tribunal. De acuerdo al fallo, este informe muestra que resultados similares al que obtuvimos se obtienen si la fecha de "quiebre" se propone en cualquier trimestre entre el último de 2001 y el primero de 2003, y también si se "reorganizan" los grupos de Isapre coludidas y no coludidas. Así, concluye el fallo que los resultados del informe de la fiscalía no permiten identificar aquellas empresas que participaron del supuesto acuerdo.

Esta afirmación es correcta, pero el fallo ignora que, por la naturaleza estadística del ejercicio realizado en el informe, no es ni puede ser el objetivo del mismo identificar el momento de inicio del acuerdo ni el grupo de Isapres coludidas. La identificación de las Isapres requeridas y del momento del "quiebre" proviene de la sustitución de planes, y es esperable que si se cambia alrededor del periodo de quiebre y si se altera ligeramente la composición de los grupos (como intercambiando una de cada grupo) los resultados sean estadísticamente similares.

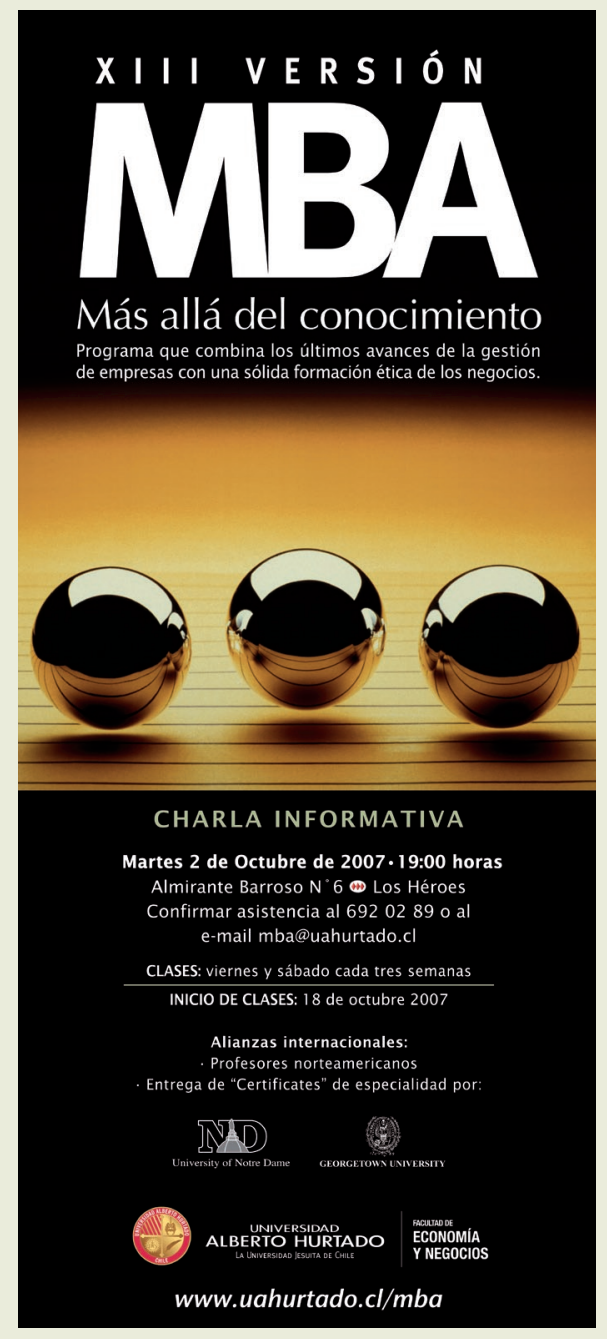

El citado ejercicio que critica la robustez de nuestros resultados se basa en 15 configuraciones alternativas de los grupos de cinco Isapres (las requeridas) y cuatro no requeridas. Naturalmente, cabe preguntarse (aunque el Tribunal no lo hizo) sobre la robustez de este ejercicio de robustez: se presentaron los ejercicios de sólo 15 configuraciones alternativas de las posibles $125 \ldots$ ¿.Por qué curiosa razón tanto el informe de Consalud como el Tribunal omiten 110 de 125 configuraciones?

¿Y qué hay de la evidencia respecto a la tasa de margen operacional? El informe de la Fiscalía muestra que la tasa de margen operacional de todas las Isapres aumentó después de consumada la sustitución de planes.

Aunque el Tribunal analiza la "tasa de siniestralidad" definida más arriba -que guarda efectivamente una relación con la tasa de margen 


\section{Observatorio Económico}

operacional que analizamos nosotros en el estudio-, ella es considerada antes de 2002 como posible justificación del cambio de planes "80/100" por "70/90” y después como un posible indicio del éxito en el control del riesgo moral. El análisis que realizamos en el estudio compara la evolución de la tasa de margen operacional de las Isapres requeridas y de las no requeridas. Lo que hallamos es que ambas aumentan después del supuesto acuerdo, lo que es consistente con la hipótesis de colusión e inconsistente con la de competencia.

Respecto a la tasa de traspasos de afiliados, la hipótesis colusiva indica que dentro del grupo de requeridas debiera haber disminuido, ya que es una variable de resultado que, aun si se ignora en qué dimensiones compiten las Isapres, refleja la intensidad con que lo hacen. Por el contrario, si la competencia hubiese sido igual de intensa en el periodo de supuesta colusión, entonces la tasa de traspasos no debiera haberse modificado. Los resultados que presentamos en el informe de la Fiscalía evidencian una disminución que avala la hipótesis de colusión. El ejercicio controla por características de cada empresa, por variables estacionales, de tendencia y por shocks que pudieran haber afectado a toda la industria. No controla, sin embargo, por algún factor genérico y asimétrico que, en un contexto de incertidumbre y justo alrededor del segundo trimestre del año 2002 pudiera haber afectado precisamente a las Isapres requeridas y no a las otras. Cuesta imaginar cuál sería ese factor...

El fallo de la mayoría, violando el deber que impone la regla de la Sana Crítica, no se pronuncia respecto a la evidencia presentada sobre la disminución en los traspasos de afiliados al interior del grupo de Isapres requeridas. ¿Por qué?

\section{Master of Arts in Economics}

\section{ILADES / GEORGETOWN UNIVERSITY}

\section{Give \\ UNIVERSIDAD \\ ALBERTO HURTADO \\ LA Universidad Jesuita de ChILE}

El Programa de Postgrado en Economía es conducente

al grado académico de "Master of Arts in Economics" (MAE),

que otorga Georgetown University y al grado de Magíster

en Economía que otorga la Universidad Alberto Hurtado.

\section{El programa presenta tres variantes:}

- Programa General

- Programa con Mención en Políticas Sociales (Public Economics)

- Programa con Mención

en Economía de Empresas (Business Economics).

\section{A Modo de Conclusión}

Chile ha avanzado mucho durante los últimos años en mejorar la institucionalidad y las capacidades de los organismos que velan por la libre competencia. Dentro de estos avances, hay que destacar la creación del Tribunal de la Libre Competencia en reemplazo de las comisiones Preventiva Central y Resolutiva. A diferencia de las antiguas comisiones, el Tribunal tiene jueces especializados (abogados y economistas), elegidos en concurso público y por sus méritos, quienes además dedican media jornada a su labor de jueces y son remunerados (a diferencia de los antiguos comisionados, que eran designados por el gobierno o elegidos por sorteo, trabajaban ad-honorem y le dedicaban pocas horas a la semana a esta labor).

Sin embargo, este fallo demuestra que queda todavía camino por recorrer, en particular respecto a la capacidad de poder condenar prácticas colusivas, ya que los acuerdos entre empresas para fijar calidades inferiores o precios superiores a los perfectamente competitivos son difíciles de detectar.

Aquí hay lecciones en dos ámbitos. Por un lado, es necesario contar con una Fiscalía Nacional Económica con la capacidad y atribuciones para poder perseguir carteles y entregar evidencias duras de acuerdos colusivos cuando estas existan: grabación de conversaciones, e-mails, faxes o archivos en los discos duros de los ejecutivos de las empresas, entre otros. Por otro lado, es necesario que el Tribunal de la Libre Competencia falle efectivamente de acuerdo a la sana crítica, respondiendo explícitamente a todas las pruebas y argumentos utilizados en el caso, utilizando análisis económico que refleje el estado del arte en el conocimiento de la ciencia económica (y no contradiga sus teorías más básicas) y justificando de maneras consistentes con la lógica sus sentencias.

En este sentido, el propio fallo de minoría desliza una crítica a la sentencia al afirmar que los jueces de mayoría no presentan una explicación única, alternativa a la de colusión, que justifique los hechos acreditados en un ambiente concreto de competencia; sino que los hechos acreditados son justificados con hipótesis diferentes y, a juicio de los ministros de minoría, poco plausibles e inconsistentes unas con otras.

La Fiscalía necesita más atribuciones y el Tribunal más razones. 